\title{
Tooth Triplet: A Rare Case Report
}

\author{
Puneet Goenka, Samir Dutta
}

\section{ABSTRACT}

A rare case of fusion of two deciduous teeth with a supernumerary tooth is reported. The fused teeth were causing deviation of the path of eruption of the permanent tooth. Thus extraction was planned for them. The histological section of the extracted tooth confirmed the phenomenon of fusion. Long term follow up showed normal eruption of the permanent tooth there after.

\section{Contact Author}

\section{Dr. Puneet Goenka}

E-mail : drpuneetgoenka@yahoo.com

Key words: Fusion, Supernumerary tooth

J Oral Health Comm Dent 2009;3(1):3-5

$\mathrm{F}$ usion also termed as Synodontia arises through union of two or more normally separated tooth germs. This union may be complete or incomplete depending on the developmental stage of the teeth at which it occurs. If it occurs before the beginning of calcification the union will be complete with the formation of a single large tooth(1). Complete fusion may be characterized by a single pulp chamber and a single root canal or a single pulp chamber and two separate root canals or a separate pulp chamber as well as root canals $(2,3)$. If the contact of teeth occurs later, when a portion of the tooth crown has completed its formation, there may be union of the roots only. The tooth may have separate or fused root canals. The dentin, however, is always confluent in cases of true fusion(1). Fusion has been more commonly reported in deciduous dentition as compared to permanent dentition(4). In addition to affecting two normal teeth, fusion may also occur between a normal tooth and a supernumerary tooth(1). Supernumerary tooth is an infrequent finding in deciduous dentition with the prevalence rate of $0.2-0.8 \%(5)$. Thus fusion of a normal tooth with a supernumerary tooth in deciduous dentition is even rarer to see. Presented here is a report of case in which two normal deciduous teeth were fused with a supernumerary tooth thereby forming a tooth triplet.

\section{Case Report}

A six and half year old boy accompanied by his parents reported to the Department of Pedodontics, Government Dental College, Rohtak with a chief complaint of palatally erupting permanent tooth. On examination it was observed that an abnormally large tooth was present in the region of maxillary left central incisor and the permanent maxillary left central incisor was erupting palatal to it (Fig. 1). Further examination revealed that a supernumerary tooth was present between the maxillary left deciduous central and lateral incisor and all three teeth were fused to each other (Fig. 2). Roentgenographic image confirmed the presence of the supernumerary tooth and its fusion with the adjacent two teeth (Fig. 3). However the degree of fusion was not clear in the radiograph.

Considering the poor prognosis of the tooth and the eruption status of the dentition decision was made to extract the fused primary teeth. Extraction was done under local anesthesia and the socket healed uneventfully. No appliance was given as the erupting permanent central incisor was not in cross-bite and showed an acceptable overjet.

Examination of the extracted tooth showed a complete fusion of the supernumerary tooth with the primary central and lateral

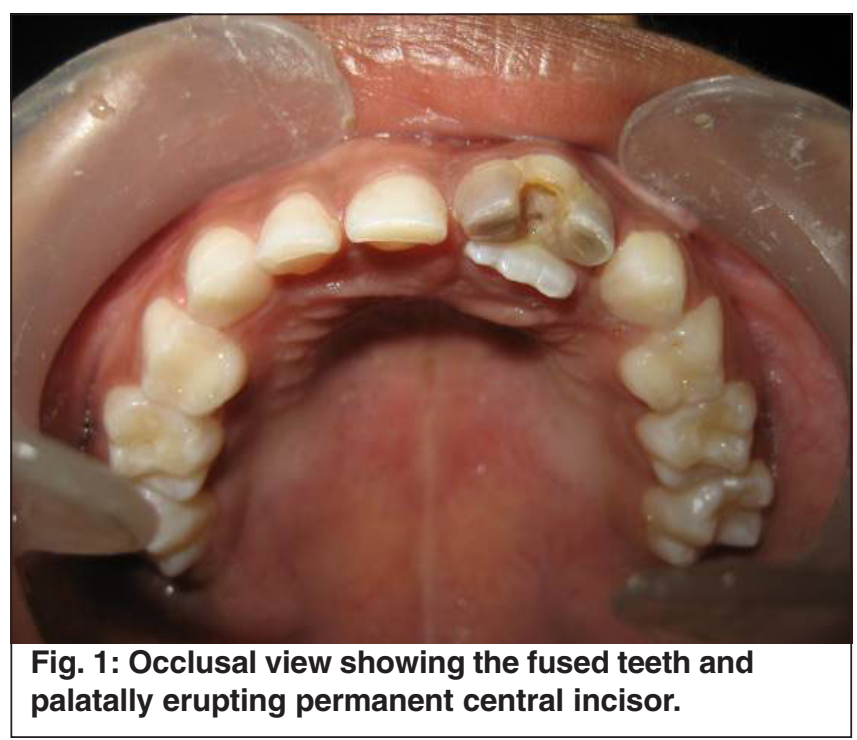




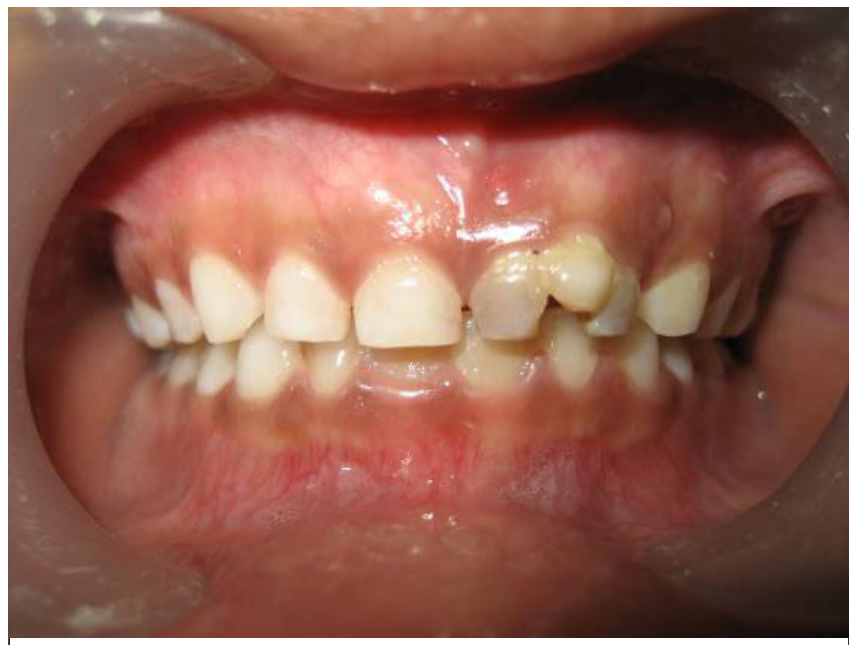

Fig. 2: The fused teeth as seen from front

incisor. Deep grooves were present in the crown portion representing the site of fusion. In the radicular portion the cementum was confluent with no grooves present (Fig. 4,5). Histological section of the tooth revealed the presence of a single pulp chamber with three separate root canals. Dental caries was present extending in to the pulp. Sign of root resorption was obvious on the lingual surface of the root (Fig. $5)$.

Patient was kept on a regular recall to monitor the eruption of the permanent dentition.

\section{Discussion}

Fusion and gemination are developmental anomalies with inherently bizarre anatomy. These anomalies may develop during tooth bud morpho-differentiation as a result of a developmental aberration of both the ectoderm and mesoderm(6). Brook and Winter elucidated the difficulty of deciding whether a tooth is fused or geminated and proposed that these anomalies be referred to in a neutral term, such as "double teeth"(7). Definite categorization of joined teeth as either germination or fusion however is often difficult(8). Several clinical and radiographic criteria are used to distinguish fusion from gemination. Fusion is the incomplete attempt of two tooth buds to fuse into one, whereas gemination is the incomplete attempt of one tooth bud to divide into two. Clinically when the joined teeth are counted as one, a full complement of teeth usually means that the phenomenon represents gemination; less than full complement of teeth usually indicates fusion. In our case when the total number of teeth were counted in the maxillary arch it was found to be 9 deciduous teeth, first permanent molars on both the sides and the left central incisor were in eruptive stage (Fig. 1), thus suggesting the phenomenon of fusion in the deciduous component. A radiographic consideration is the difference in the root configuration often seen between fusion and gemination. In case of fusion there are usually two separate canals, whereas in gemination there is usually one large common root canal $(8,9)$. In our case the intra-oral peri-apical radiograph was not very contributory but the histological section revealed that the fused teeth had a single large pulp chamber with three separate root canals thus suggestive of fusion.

The etiology of fusion is not yet clear. The most common belief is of some physical force or pressure causing contact of the developing tooth germ(1). This may be the possible cause of fusion in our case also. The presence of a supernumerary tooth between the central and lateral incisor would have caused lack of space thus resulting in to its contact with the two adjacent developing tooth germs.

Other investigators consider a viral infection during pregnancy and use of thalidomide as the possible cause of the anomaly(10). An animal study has found hypervitaminosis A as the cause of fusion(11). Still others have considered the role of heredity in this condition(2,3). Fused teeth are usually asymptomatic, but can cause a number of clinical problems like delayed exfoliation thereby deviating the path of eruption

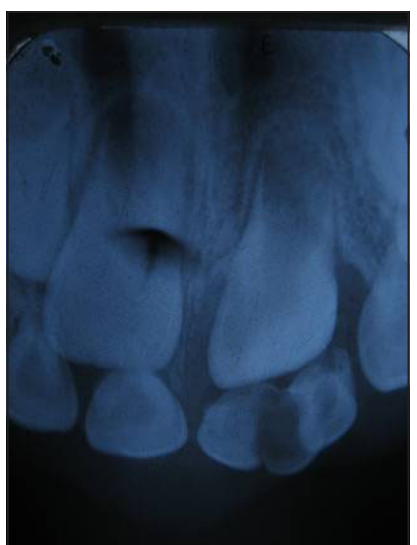

Fig. 3: Radiograph showing fused teeth

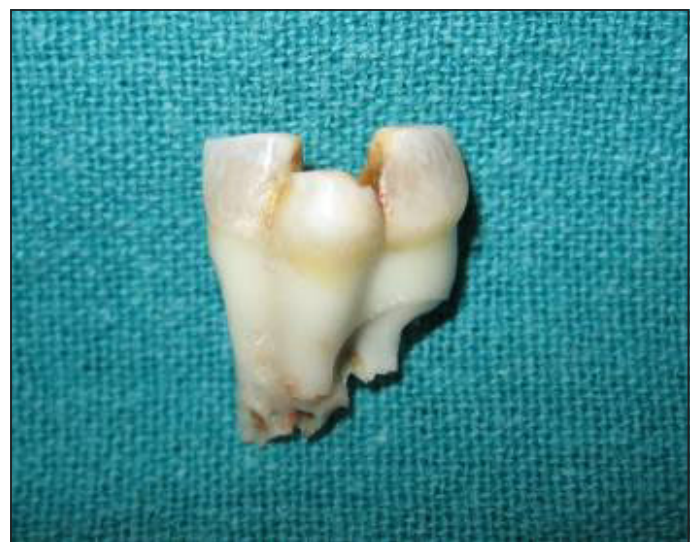

Fig. 4: Extracted teeth

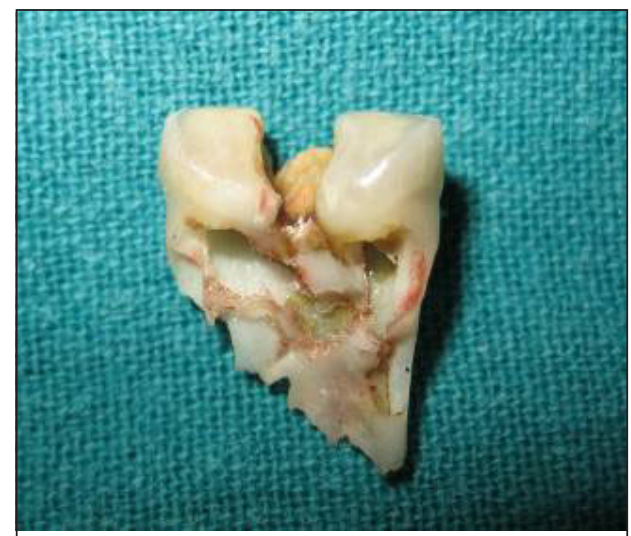

Fig. 5: Palatal view of the extracted teeth showing resorption of the root 
of permanent successors, caries in the grooves at the site of fusion and severe esthetic problems $(7,12,13)$. In deciduous dentition if there is delayed exfoliation or if the fused tooth is resulting in to deviation of the path of eruption of the permanent successor, extraction of the fused tooth is the best treatment option. In case of simple caries the tooth can be restored easily but in cases of pulpal involvement the bizarre root anatomy makes pulp therapy difficult. In our case the fused tooth was causing slight deviation of the erupting permanent central incisor. In cases where there is a marked deviation the permanent successor may erupt in cross-bite. In such cases the fused tooth should be extracted and an appliance should be given to correct the cross-bite. In our case there was absence of crossbite with an acceptable overjet thereby not necessitating any appliance therapy.

In cases as the one described above proper oral hygiene should be encouraged to prevent caries and the child should be regularly monitored to ensure a normal eruption pattern of the permanent dentition.

\section{THE AUTHORS}

\section{Dr. Puneet Goenka}

Post Graduate student

Deptt. Of Pedodontics \& Preventive Dentistry,

Govt. Dental College,

Rohtak, Haryana, India

drpuneetgoenka@yahoo.com

Corresponding Author

Dr. Puneet Goenka

\section{Dr. Samir Dutta}

(MDS)

Sr. Professor \& Head

Deptt. Of Pedodontics \& Preventive Dentistry,

Govt. Dental College,

Rohtak, Haryana India

\section{REFERENCES}

1. Shafer WG, Hine MK, Levy BM. A textbook of oral pathology $4^{\text {th }}$ Ed, Tokyo, WB Saunders Co. 1993; 38-39.

2. De Jonge JE, Levitas TC. Gemination, fusion, twinning and concrescence. J Dent Child 1965;32:93-100.

3. O'Reilly PMR. A structural and ultrastructural study of a fused tooth. J Endod 1989;15:442-46.

4. Grahnen H, Granath LE. Numerical variations in primary dentition and their correlation with the permanent dentition. Odontol Revy 1961;12:348-357.

5. Winter GB, Brook AH. Tooth abnormalities in clinical dentistry, eds Rowe AHR, Alexander G, John B. Blackwell Scientific Publications 1971;38:390-98.

6. Agnihotri A, Marwah N, Goel M. Geminated Maxillary Lateral Incisor with Talon's Cusp-A Rare Case Report. J Oral Health Comm Dent 2007;1(2):40-42.

7. Brook AH, Winter GB. Double teeth. A retrospective study of geminated and fused teeth in children. Br Dent J 1970;129(3): 123-30.

8. Prabhakar AR, Marwah N, Raju OS. Triple Teeth: A case report of an unusual fusion of 3 teeth. ASDC J Dent Child 2004;71:32-5.

9. Grover PS, Lorton L. Gemination and twinning in the permanent dentition. Oral Surg, Oral Med, Oral Pathol 1985;59:313-8.

10. Kurihara Y. Studies on the teeth from thalidomide baby. Jpn $J$ Pediatr Dent April 1963;1:68-74.

11. Knudsen PA. Fusion of upper incisor at bud or cap stages in mouse embryos with encephaly induced by hypervitaminosis $A$. Acta Odontal Scand 1965;23:549-65.

12. Turkheim HJ. Two cases of fused incisors in the deciduous dentition. Br Dent J 1949;87:41-43.

13. Knapp JF, Mc Mohan JI. Treatment of triple tooth: Report of a case 1984;109:725-727. 